\title{
12. The playful scientist: Stimulating playful communities for science practice
}

\author{
Ben Schouten, Erikvan der Spek, Daniël Harmsen, and Ellis \\ Bartholomeus
}

\begin{abstract}
In this chapter, the authors elaborate on serious games and playful interactions in modern scientific practices, and on the way they can engender mutual scientific growth. They use a research-through-design approach, in which three possible scenarios and prototypes are studied to envisage the new role of the public library in practicing science in a changing society. Their conclusion is that the public library of the future should employ citizen science projects that are fun, accessible, malleable, and participatory, so that its new role can focus on offering meaningful information at the right time in the right place, contextualizing information using playful solutions, bringing together communities to share information, and enabling new scientific practices in unexplored fields.
\end{abstract}

Keywords: Citizen science games, playful, research through design, public library

Traditional methods for practicing science rely mainly on experts. However, newer forms of science practice have started to allow for non-experts to participate as well, a trend mirrored in societal change toward more participatory cultures. Citizen science projects exist in various forms and offer many ways for the public to participate. What most of these projects have in common is that participants contribute to scientific activities made available by experts through apps and desktop applications. What these projects often lack is the community building that allows the science projects

Glas, R., S. Lammes, M. de Lange, J. Raessens, and I. de Vries, eds. 2019. The Playful Citizen. Civic Engagement in a Mediatized Culture. Amsterdam: Amsterdam University Press. DOI: 10.5117/9789462984523/CH12 
to be meaningful for the citizen participating. In this chapter, we want to elaborate on serious games and playful interactions in these modern science practices, and look at the way they can engender mutual scientific benefit. We used a research through design approach; more specifically, we have designed three possible scenarios and prototypes to envisage the new role of the public library in science practice in a changing society.

Our starting point in this chapter is the current state of the art in what can be called citizen science. Citizen science (also known as crowd science, crowd-sourced science, civic science, or networked science) is scientific research conducted, in its entirety or in part, by amateur or non-professional scientists, often by crowd-sourcing and crowdfunding. In this chapter, we would like to address the practice of citizen science as part of the changing role of scientific institutions such as the public library. Funded by a research grant from the city of Eindhoven (the Netherlands), we studied several alternative roles for the library as an institute designed to cultivate knowledge and scientific literacy among the city's citizens.

We challenged a group of students at the Department of Industrial Design at the Eindhoven University of Technology to design a series of (playful) citizen science scenarios in which there is a clear role for the public library. In addition we invited an industrial partner, IJsfontein from Amsterdam, to join the consortium as a designer in residence. In this way, we want to bolster the ecosystem of the creative industries in the Netherlands, especially in bringing together the different stakeholders to co-create applications for social innovation.

The methodology that we used is that of research through design. Research through design is about creating knowledge through actionreflection with prototypes in a design process (Jonas 2007). Insights from these intermediate results (prototypes) are used to create more general conclusions (Sein et al. 2011). To reflect on the possible role of the library and citizens we (iteratively) designed prototypes followed by reflection, analysis, and synthesis. We wanted to focus on the process of experiential learning by citizens themselves within a participatory setting, as opposed to a more classical approach of consulting an expert or knowledge base made available by the public library. In this chapter, we would like to elaborate on how playful citizen science can impact the process of knowledge gathering, the configuration of knowledge itself, and the way knowledge is applied and shared. 


\section{State of the art in science practice}

The World Wide Web has gradually grown as a source of information; much of the knowledge taught in schools can be found readily and ondemand on the internet, through online encyclopedias such as Wikipedia, social networks and internet forums. This socially distributed, collective intelligence (Lévy 1997) afforded by the internet may obviate the need for a large active knowledge base. However, it also has its downside. For one, it requires a new way of thinking about (and the education required to cope with) this hyper-connected world, often encapsulated in what is called twenty-first century skills and new media literacy (Jenkins 2009). Among these twenty-first century skills, problem-based learning is often employed and emphasis is placed on sense-making in authentic contexts (Lombardi 2007). In addition, as young people grow up constructing knowledge from various (often highly-pleasing sensorial) trans-medial sources, traditional instruction can be considered boring from their perspective.

Members of the millennial generation increasingly show a lack of motivation to learn with classical skill and drill practices (Ryan and Deci 2000; Deen and Schouten 2011) and prefer a more experiential and social approach to learning (Oblinger and Oblinger 2005). They generally spend more time using screen media, distracting them from their studies (Jenkins 2009). To encourage more autonomy-supportive educational practice is generally accepted as the best way to create more intrinsically motivated students (Deen and Schouten 2014).

As young people find things that intrinsically motivate them, they often join online communities, also called affinity spaces (Gee 2005; Schouten 2015), where they can share knowledge and skills pertaining to their interests with other people from across the globe. People share and learn from lifehacks' on YouTube and exchange elaborate co-constructed architectures and virtual landscapes in Minecraft (Mojang 2011). This participatory culture, in turn, shapes the worldview, or epistemic frame, of its community members (Shaffer 2006).

However, the internet as a knowledge base is fragmented and data are not always provided in a clear context. Moreover, while democratized cultures of participation can lead to creativity, it is well known that learning without proper guidance (there are typically no experts in grassroots movements who can provide guidance) can send people down "garden paths" (Gee 2004), meaning the epistemic frames that are formed may be skewed. Furthermore, in the last decennium, we see another development where interaction has 


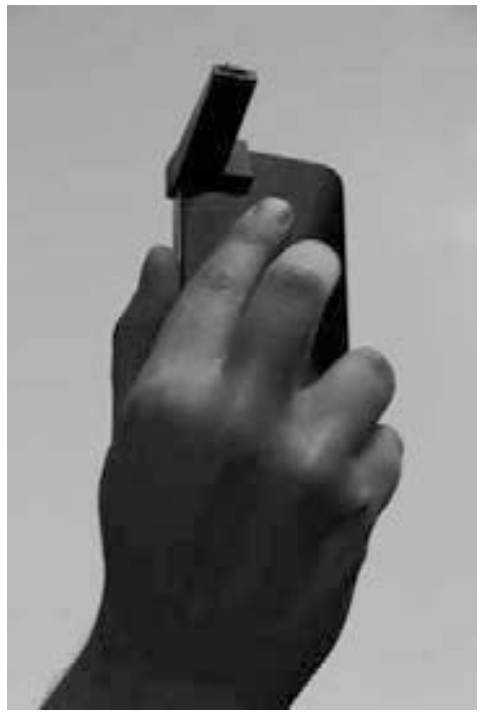

12.1: A smartphone with the Ispex add-on.

contributed to processing information, for instance in computer games and apps. Or, to put it differently, in addition to the vast amounts of data made available by the use of sensors installed on run-of-the-mill smartphones, now everybody can become a scientist. For instance, in Ispex (Figure 12.1), a simple smartphone is used in combination with an add-on device to measure air pollution in the atmosphere. The resulting data is aggregated over thousands of devices in order to draw maps and identify the most polluted areas that can pose potential risks to the health of individuals.

In these applications, there is a clear shift from just gathering data to processing the data into meaningful information that can empower citizens. One thing became clear in our research effort, citizen science makes it more fun for people to contribute to science and the main reason why citizens want to participate with applications such as Ispex, besides curiosity, is that they feel they can add (personal) value to society by contributing in some way.

In summary, a number of trends can be discerned. We see 1) that the World Wide Web seems to obviate the need for a knowledge base and classical information institutions such as libraries; 2) a shift to a participatory culture where citizens want to contribute within affinity spaces where groups of people are drawn together because of a shared commitment to a common activity; and 3) citizens of the millennial generation need expert guidance in acquiring a proper epistemic frame pertaining to their affinity space. 
In the next section, we contend that cultivating and nurturing these cultures of science participation within affinity spaces can be a valuable new role for the public library, and that games and playful design offer ways to achieve this.

\section{A symbiotic relationship through playful science}

Games can play an important role, both as a means to motivate the citizen to engage in citizen science projects, but also to create real value for the citizen scientist through the engendering of complex learning, scientific skill acquisition, and empowerment. Games are so engaging because they satisfy the basic psychological needs of competence, autonomy, and relatedness (Przybylski, Rigby, and Ryan 2010). Through a process of encountering problems and autonomously finding ways to overcome them, the game player feels that they become more competent and is more likely to engage subsequently in the activity (Van der Spek 2012). What is more, the persuasive nature of games (Bogost 2007) has been shown to be a powerful tool for inducing attitude change (Wouters, Van der Spek, and Van Oostendorp 2009). Being engaged in collaborative science games can not only increase a person's knowledge about the subject, it can also improve his or her disposition toward science and learning. Related to this, science games can let players experience being a scientist, thereby acquiring the epistemic frame of a scientist and learning how to think scientifically (Shaffer 2006). Apart from being fun, games are experiential sense-making tools, where players immersed in the game learn about complex systems, at their own pace and volition, thereby acquiring the necessary cognitive skills to deal with increasing complexity (Squire 2003).

These aforementioned affordances are important for the concept of citizen science and in our case, the new role of the public library, for two main reasons. One is data, because as the possibilities of capturing data increase, so too do the complexities of dealing with it. With the internet, the Internet of Things, and big data as key concepts in the new information age, the necessity of having a large set of declarative knowledge decreases; however, the need for relevant cognitive skills and attitudes in order to deal with the ubiquitous complexity increases. Games are ideal ways to train for these skills and attitudes (Zimmerman 2007). While participating as individual players in a pervasive game of crowd-sourced information at different places, they also learn about the pervasiveness of individual information bits constituting a complex system. The feedback provided by the overarching game can then be used to comprehend the compound system and train for the skill 
of systems thinking. In addition, playing with these systems stimulates an improvisational and creative attitude necessary to operate in a world with ill-defined complex problems (Lombardi 2007; Zimmerman 2007).

For this reason, the new library can most accurately be envisioned as an institute, which focuses on (playful digital) interactions; predominantly digital, occasionally traditional, often serious, sometimes fun. The new library creates and curates affinity spaces where citizens can come together and contribute to science, and where games are used to make the process engaging, playful and more meaningful for these citizen scientists. This relates to the twenty-first century skills with which citizens self-organize social practices and learning, based on civic-driven change that 1) supports bottom-up approaches instead of top down decision making; 2) enables co-creation, allowing a large audience of users and experts to participate; 3 ) incorporates wisdom of the crowd and agent technology where information and decisions can come from many sources; and 4) provides a more dynamical and balanced way of research, less restricted by fixed rules or regulations.

\section{Game design to improve citizen science uptake}

While there is great potential for the many uses of citizen science, its efficacy is often hampered by the one-directedness of its value proposition. Clearly the scientist benefits from contributions (such as large data sets) freely provided by the general public, but what does the citizen stand to gain? Citizen science projects try to make contributing (to science) more fun and create a longer lasting appeal by adding playful elements for the participants. The game Foldit (University of Washington Center for Game Science/Department of Biochemistry 2008), for instance, is described in Wikipedia as

an online puzzle video game about protein folding. The objective of the game is to fold the structure of selected proteins to the best of the player's ability, using various tools provided within the game. The highest scoring solutions are analyzed by researchers, who determine whether or not there is a native structural configuration (or native state) that can be applied to the relevant proteins. Scientists can then use such solutions to solve 'real-world' problems, by targeting and eradicating diseases, and creating biological innovations. (Wikipedia 2015, n.p.)

Some citizen science projects have incorporated additional game elements. These elements are often basic and are usually an added feature instead of a focus point. In most projects, these elements are achievement-based, 
where participants need to perform an action a certain number of times to gain points or proceed to more advanced levels. An example of this can be found in Cornell Lab of Ornithology's CamClickr project, ${ }^{1}$ which

uses basic gaming technology to provide a friendly spirit of competition. In level 1, the participant receives one point for each image sorted into an album (e.g., eggs, nestlings, or adults). After participants sort 99 images, they can move on to level 2 and earn four points for every tagged image. The challenge in level 2 is to classify each image with behavioral tags such as feeding young, preening mates, and incubating or rotating eggs. (Cornell Lab of Ornithology 2008)

While Foldit contains puzzles that can be intrinsically and cognitively interesting, most of the other citizen science projects primarily rely on isolated, superficial gamification principles such as competitive scoring mechanisms to keep the player engaged. This 'pointsification' (the scoring of points as the sole motivation to play) as an extrinsic reward can stimulate perseverance to complete an arduous task, but is only partially what games are about (Robertson 2010). There is little in the way of stimulating the player's fantasy (Malone 1981) or of providing moment-to-moment 'game feel' in the interaction (Isbister 2011). This means that a player already has to be motivated to start playing the game, the game itself does not provide a lot of meaning to the player. The community is sustained, but does not rise above itself.

Projects such as CamClickr, Foldit, and EyeWire (Wired Differently 2012) all claim to be games, but because their game elements (such as pointsification) do not add much fun or playfulness, we find it difficult to call these applications games. Moreover, these applications are what we call expert systems, meaning that results contribute to the knowledge base of the initiator and cannot be freely interpreted by users. Citizen science projects that are intrinsically fun because they contain game elements (such as storytelling) are rare. However, this does not mean that citizen science projects are not fun. Other aspects can make the projects attractive to people such as having a personal interest in the subject or providing a sense of accomplishment and making a larger contribution, as well as being part of a community or creating the opportunity for exploration.

1 CamClickr was launched in 2008. This project catalogues nesting behavior of birds captured in over 600,000 images. The resulting imagery led to the publication of one scientific article and CamClickr was featured in a biology curriculum (Vos and Cooper 2010), using a free online citizen science project to teach observation and quantification of animal behavior. 


\section{A future role for citizen science}

In this section, we want to discuss a design research project entitled KLOS developed at the Eindhoven University of Technology to elaborate on more advanced functionalities and future scenarios for citizen science projects, using applied gaming and playful interactions. ${ }^{2}$ The idea is to build (digital) playful labs for science practice, with the purpose of acquiring skills which in turn are organized and synthesized by the public library.

KLOS is a Citizen Science in Urban Gaming research project set up with cooperation by the Eindhoven University of Technology, the city council of Eindhoven, the public library of Eindhoven, and finally IJsfontein (Amsterdam), an industrial partner interested in participating in playful interaction design and research. As part of the Dutch government's new policies to cultivate collaborative relationships between industry, research, and government (known as the triple helix), this initiative resulted in the appointment of a designer-in-residence from the industry to Eindhoven University, for half a year. The starting point of the project was the following research question: How can citizen science and urban gaming contribute to the collaborative creation and dissemination of experiences to educate and obtain skills in several domains and how can the public library Eindhoven contribute to this new role?

Our students approached the research question by adopting a methodology of Reflective Transformative Design in order to obtain disruptive innovative systems (Hummels and Frens 2011). By imagining a different world, they try to break free of current constraints and try to come up with unique new products and services. We challenged around 25 students from Eindhoven University and Fontys University of Applied Sciences to design prototypes for the 'Library of the Future.' Over the course of thirteen weeks, the students worked in teams under the supervision of a professional expert. Together with supervisors and staff of the university, the students' design processes were observed and their concepts and questions were discussed. In the next section we will elaborate on some of the design cases.

2 KLOS refers to the Dutch expression 'Kennis Ligt Op Straat,' which roughly translates to 'Knowledge can be found everywhere'. 

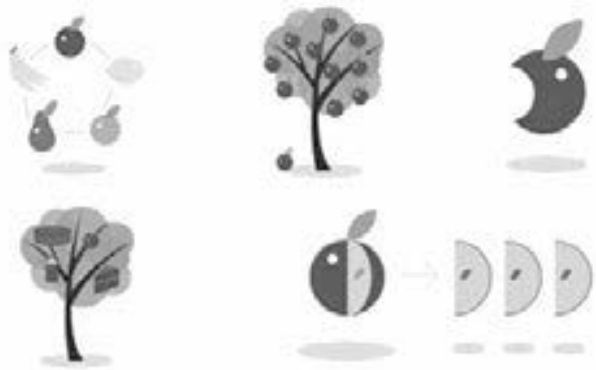

12.2: During our design process, we envisioned the new role of the library, using the metaphor of a tree bearing fruits that can be harvested, re-seeded, and consumed, in reference to the different roles of the library: dissemination, education, and utilization.

\section{The library of the future}

As part of our efforts to contribute to the triple helix policy, strengthening the collaboration between research institutes, industries, and governmental bodies, we invited a designer in residence from the renowned industrial partner IJsfontein. The role of the designer was to reflect on the newly proposed concepts delivered at the later stages and develop a final proposition for the public library to be realized after the initial research projects.

We envisaged the Library of the Future as a new type of institute designed to address the needs of a new type of citizen. In a future, when knowledge is just a finger tap away, this new institute will help develop twenty-first century skills, such as connected collaboration, critical thinking, and creativity. So, what is it precisely? The Library of the Future can most accurately be described as an institute focusing on skills and attitudes. Its services change constantly as people interact with it, much like the boundaries of science constantly change as we explore new fields. In traditional learning and skill and drill exercises with books, knowledge is transmitted to those willing to learn. In most of these cases there is a lack of interaction during the transfer of knowledge. The student simply 'consumes'.

The Library of the Future is different. Using the metaphor of a tree, it behaves like a fruit-bearing tree, with fruits of knowledge, skills, and attitudes (see Figure 12.2). Citizens can pick the fruits, harvest the seeds, and then plant trees of their own, feeding back into the system. The citizen will create the actual structure of this knowledge base and the library acts as the community gardener, introducing relevant playful activities and providing ties to pertinent experts. 

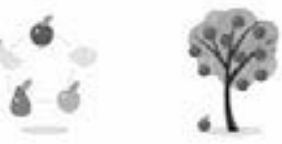

12.3: Different kinds of fruit, with one corresponding tree.

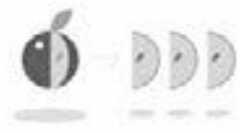

12.5: Connecting sections of fruit.

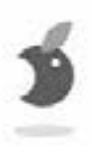

12.4: Fruit out of context.

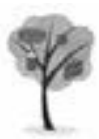

12.6: Tree that bears alternative produce.

Another key shift of the Library of the Future is one of teaching skills for learning by oneself as opposed to offering knowledge. Citizens of the future might only need to learn where information can be found when they need it, and they should be focused on learning practical skills and working on new ways to access knowledge. To be more precise, the new services of the library will help facilitate 1) how meaningful information can be retrieved; 2) how data can be processed, used, and contextualized; 3) how information can be shared and thus contribute to science; and 4) how education and exploring new areas of research can be encouraged. We see the library as a dynamic system with several features, namely excellence, wisdom, conjunctive and connected, and contemporary.

\section{Excellence}

The primary function of the library is to create meaning and context for citizens and offer them twenty-first century skills such as critical thinking, creativity, and the ability to solve problems. The constant 'hunger' for information will be put in context. The role of the library is to bring quality to the process. Knowledge is levered, giving a sense of what you want to know or should want to know. The library offers suggestions on where to go next in your quest for information. It is important where the right 'knowledge' tree can be found (see Figure 12.3). As an example, in the future, this could be the latest augmented reality apps that enable a user to simple scan an object, a building, a word, and find useful information about it.

\section{Wisdom}

If you know where to look, you have a very good chance of finding the answer online. But this 'quick fix' answer lacks any context (see Figure 12.4). You can 
google 'how long to boil corn?' and find the precise number of minutes. But it teaches you nothing more about cooking, nor does it suggest where to go from there. Knowledge has become common with the help of the internet and mobile handheld devices. There is almost too much now. Sometimes it is hard to assess the quality of it, or to form an opinion on a subject. The Library of the Future will be focused on providing expertise and helping to process information.

\section{Conjunctive and connected}

The library tries to connect citizens by finding other people who have similar interests (see Figure 12.5). It also allows experts who are knowledgeable to find interested civilians and vice versa. The process can work both ways. An expert might be in need of fresh ideas, reviews, or just a lot of data. A citizen might have a brilliant idea but needs help to develop it. The Library of the Future will be a knowledge broker, facilitating the connection between citizens and experts alike. In many ways, everyone will be able to become an expert.

\section{Contemporary}

The Library of the Future will provide new ways to practice science, as it wants to support bottom-up approaches of research (starting with the user) instead of top-down research. This will allow entirely new and alternative bodies of knowledge to be developed (see Figure 12.6). New experts, no matter how insignificant they might feel, can add new insights and knowledge to the library and can be found by anyone within the system.

The future will hold entirely new products not yet designed. Each product will be tailored to transfer specific expertise in the best and most efficient way possible. Increasingly, more devices will be connected to other devices, allowing for even more exciting capabilities and for a much greater focus on making knowledge accessible, more interactive, and fun. In the next section, we will examine three example projects that the Library can host in the future.

\section{Examples of playful science practice}

In this section, we will show how the requirements discussed above resulted in various design projects. We studied three of the projects, based on differing expertise: 1) Music experience (Rhytmos); 2) the art of debating (Battle 
of Wits); and 3) science education (Blob). We analyzed them according to seven different factors (see Table 1).

Table 1: Projects and analytical factors

\begin{tabular}{|c|c|c|c|}
\hline & Rhytmos & Battle of Wits & Blob \\
\hline Fun factor & ++ & ++ & + \\
\hline $\begin{array}{l}\text { Playful learning and } \\
\text { critical thinking }\end{array}$ & ++ & ++ & ++ \\
\hline $\begin{array}{l}\text { Empowerment and } \\
\text { bottom-up approach }\end{array}$ & ++ & + & ++ \\
\hline $\begin{array}{l}\text { Attitude change toward } \\
\text { science }\end{array}$ & +- & $?$ & ++ \\
\hline $\begin{array}{l}\text { Motivational aspects: } \\
\text { Autonomy }\end{array}$ & + & ++ & ++ \\
\hline $\begin{array}{l}\text { Motivational aspects: } \\
\text { Competence }\end{array}$ & ++ & ++ & ++ \\
\hline $\begin{array}{l}\text { Motivational aspects: } \\
\text { Relatedness }\end{array}$ & + & + & ++ \\
\hline
\end{tabular}

\section{Design case 1: Rhytmos by Milan Knust Graichen}

Objectives: The first project was targeted at understanding rhythm in playing music. The library can serve as a public music instrument where people/ citizens can learn about rhythm and the interaction between tones and tunes. It is anticipated that by playing music together in a public environment, getting connected, and experiencing the process of mutual learning, users should become more interested in playing music. The library could take an active role in contributing to peoples' music skills and their experiences of making music, instead of just simply lending music CD-ROMs and literature. In this way, the library's focus is on enabling citizens to develop and create music and obtain new skills instead of just consuming.

Description of design: Rhytmos helps people to develop rhythmic skills in a playful way. It is an LED floor on a city square with a moving line on the floor (see Figure 12.7). Depending on where you position yourself, the rhythm will change, and the player/user will understand the consequence of that position and explore its relation to other players. While some people have a natural ear for music and a sense of rhythm, not everyone is born with these skills. This urban sculpture is designed to trigger people's curiosity and invite people living in urban spaces to explore and investigate rhythm together. 


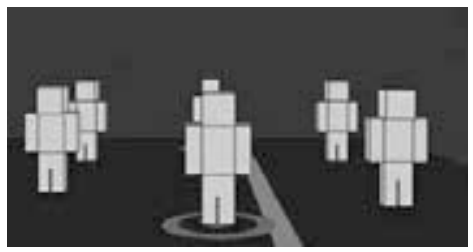

12.7: Rhytmos is a LED floor on a city square with a moving line for music experiences. The rhythm changes according to your position relative to the line and the other users.

Analysis: Providing and enabling citizens to co-create and experience music in a public space creates an engaging and collective environment in which they can explore and learn. Intrinsic motivation is triggered by curiosity. The threshold to communicate with a stranger or your neighbor is lowered. Music can elicit engagement and curiosity in itself; in this concept, people are free to participate or just be a spectator of other people who play and explore. The curiosity to understand sound interaction is engaging and playful, there are no other rules and no interaction can be wrong. Users can learn from their experience. For instance, one person who does not understand their influence in the playful interaction can have it explained so they can then be invited to explore it further.

\section{Design case 2: Battle of Wits by Doenja Oogjes}

Objectives: This project promotes the skill of debating. The library will not only provide knowledge, but the Library of the Future will enable people to build and develop their resources and play around with ideas and perspectives as parts of furthering citizen science. Critical thinking and debating exercised in a playful way can elicit creativity and perspectives or counter arguments that can be examined, since the game provides a safe environment in which no argument is ever right or wrong. But for the sake of the game, the citizen scientist/player is triggered to explore a certain mindset.

Description of design: Battle of Wits is a game meant to stimulate an open approach to gaining knowledge. The game consists of two sets of chalkboard hexagons, chalk markers, a deck of playing cards containing statement cards (with statements about current subjects or ongoing issues), and chance (see Figure 12.8). By coming up with as many original arguments as possible, players have to consider the topic from all different points of view, or at least experiment with various perspectives and lenses. The game is won when one player/team locks in the other team with arguments. 


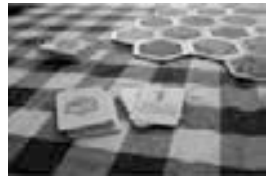

12.8: Battle of Wits is a game about debating. Your argument can be locked by arguments from the other team configured on the table.

Analysis: In this app for the Library of the Future, we focused on open access to information, citizens' skill development, relationships with peers, and critical thinking. The playful context of a game enables/allows higher contrast and freedom and more creativity to view a topic from new, different, and even extreme perspectives. It includes listening well and acknowledging other players' creativity and opinions for the sake of the discussion without being offended or becoming defensive or being concerned with who is right or wrong. Final judgment is not about being 'right,' but about being creative and open-minded.

\section{Design case 3: Blob by Sam Janssen}

Objectives: In this project, we wanted to focus on learning skills. To be more specific, we wanted to look at how the library can provide and enable children's curiosity for nature, inviting them to discover and explore their outdoor surroundings instead of experiencing the world only through digital interaction and using the computer. A second objective we had was to get children outdoors and to teach them skills of examining, questioning, unscrambling, and analyzing the world around them. The role of the library would be to 1) provide tools and devices to develop these skills; 2) be the caretaker and curator of the data collected and harvested; and 3) collect methods developed for and iterated by the users.

Description of design: Night lamp Blob becomes a child's friend and requests daily input about nature to be able to survive and shine its protective light and colors at night. Its functionalities are like those of 'Siri,' the intelligent personal assistant from Apple that helps you get things done (Aron 2011). In this case, communication and interaction are not only conducted through voice input, but also with the help of photos, audio, and ambient lighting (see Figure 12.9). The idea is that the child explores nature and takes pictures of an interesting object or specimen, after which the lamp 'asks' questions in order to comprehend the object and its larger context. The player learns to study objects more closely by reflecting on the questions asked by Blob: 


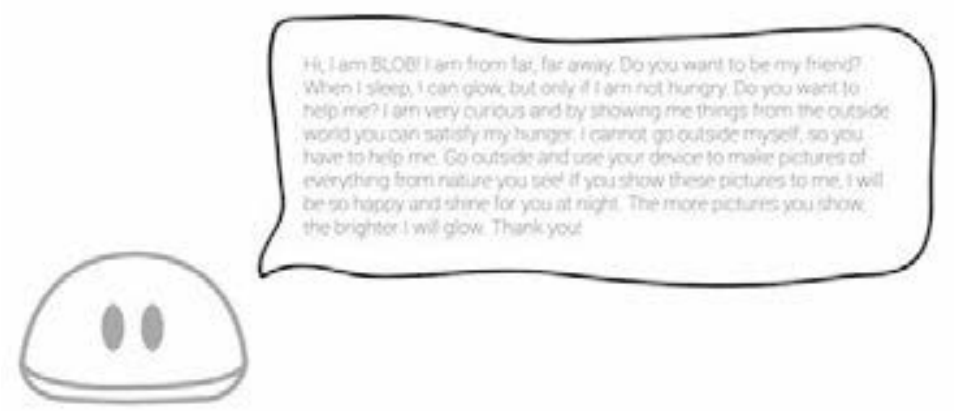

12.9: Night lamp Blob is a smart object that is able to serve as a knowledge base for children using Apple's Siri technology. The child presents photos and objects to Blob, after which the lamp gives back additional information pertaining to the objects shown.

how big, how heavy, what color, how soft? The child should be able to adopt an explorative attitude in order to acquire better learning skills.

Analysis: The child becomes motivated to connect with their very personal friend. After recognizing the benefits of knowledge, they learn to naturally explore on their own. Their efforts are rewarded by the increasing illumination of the night lamp. Meanwhile, the player becomes more aware, confident, and competent in nature since they learn about the outside world in a safe home environment with the Blob.

This collective, dynamic growth at the library will result in the collection of large amounts of big data including photos, questions, and answers. These data are literally 'food for thought' since the lamp will attempt to recognize patterns; what pictures are taken in which seasons and in what areas/locations (i.e. city or countryside) by what type of players. Little data gems can be found in the big data collected by the children who are primarily driven by curiosity to feed their night lamp. Players learn to become scientists without realizing it, since their motivation is to nourish the lamp, and only indirectly experience the growth of information. The product teaches you to question your environment and by asking you to contribute to the development of the science of nature. Moreover, the photos can also produce a lot of contextual information about natural phenomena such as seasonal characteristics and/or climate changes. 


\section{Conclusion}

The goal of current citizen science practices is to encourage larger groups of users to contribute to scientific research. It is not hard to see the benefit for scientists as well as science. However, apart from the particular research topic and its results receiving more general public attention, little meaning is created for the citizen scientist, in terms of fostering a scientific worldview, as well as in the game design employed to make it more engaging. The functionality of the state of the art projects is gathering knowledge from the public to science and not the other way around. In order for citizen science to live up to its potential, a number of factors need to be addressed to better target citizens. The first we like to mention is the fun factor. Citizen science can be fun and motivate people to contribute to science. It seems that the main reason why people participate in citizen science projects is because they feel they can add value by contributing. Citizen science projects need to make citizen contributions more fun and more intrinsically motivating, as well as trying to create a longer lasting appeal by establishing communities and affinity spaces for the participants through meaningful gamification (making the interaction more playful and/or achievement based). A second important aspect is accessibility. Projects should be made more accessible by being web-based or smartphone-based. By doing this, citizens can contribute at any time and from any location.

Another aspect we would like to put forward is ownership. At the level of scientific values, we like to mention review, verification, and filtering. In some projects, field experts review, verify, and filter people's contributions; in other projects, those who contribute most are the ones that review, verify, and filter the contributions; and in still other projects, the contributions are filtered by a computer which compares the results to filter the 'odd ones out.' In order to improve the validity of collaborative citizen scientist reviews and verification processes in future participatory cultures, more care should be invested in fostering the scientific paradigm pertaining to the affinity space these citizen scientists are participating in. We contend that entrenching the communities of citizen science practices in intrinsically motivating and meaningful games can help in reaching such a sufficient scientific level.

Citizen science projects are usually designed to be accessible to ensure as many people as possible can contribute and participate. This is done by either making the subject or field more accessible, or by making the interaction (analysis/data entry) more simple and playful! And this brings us to the role of science institutes, in this case, the public library. In line 
with the arguments discussed above, it is the library that should encourage the opportunities to practice citizen science and as a result their role should shift from archiving information to processing information to allow citizens the opportunity to participate and create meaning. This new role focuses on 1) offering meaningful information at the right time and right place as part of everyday life; 2) contextualizing information using playful solutions; 3) bringing communities together to share and network information; and 4) enabling new scientific practice in other unexplored fields.

In this project, we focused and played around with the concept of a library practising science. Our starting point was the current behavior of citizens, their needs and desires, and how to encourage the curiosity of people and how to invite people to become engaged in pursuing knowledge and skills and building their own resources to become more autonomous and deal with life's problems around us. It is clear that curiosity engages citizens and elicits learning. Besides, by being connected to others with the same interest, users experience partnership and are willing to cooperate and co-create. This could eventually result in science (or public understanding, so to say) based on alternative theories and lines of thought different from current state of the art science practices.

We all need to play more in order to learn more and hone our skills and stimulate our interest. Citizen science has the ambition to invite and enable people to co-create, participate and explore.

\section{Acknowledgments}

This research is part of the project Persuasive gaming. From theory-based design to validation and back, funded by the Netherlands Organisation for Scientific Research (NWO; 2013-2018; project number 314-99-106). We are grateful to the City Council of Eindhoven for their financial support, as well as to the students who contributed to this chapter: Robert van Kampen, Milan Knust Graitchen, Doenja Oogjes, and Sam Janssen.

\section{References}

Aron, J., 2011. How innovative is Apple's new voice assistant, Siri? New Scientist 212 (2836): 24.

Bogost, I. 2007. Persuasive games: The expressive power of videogames. Cambridge, MA: The MIT Press. 
Cornell Lab of Ornithology. 2008. CamClickr. [browser]. Cornell University. Game.

Deen, M., and B. A. M. Schouten. 2011. Games that motivate to learn: Designing serious games by identified regulations. In Handbook of research on improving learning and motivation through educational games: Multidisciplinary approaches, ed. P. Felicia, 330-351. Hershey: IGI Global. -. 2014. The differences between problem-based and drill and practice games on motivations to learn. International Journal of Gaming and Computer-Mediated Simulations 7 (3): 44-59.

Gee, J. P. 2004. Learning by design: Games as learning machines. Interactive Educational Multimedia 8:15-23.

-. 2005. Semiotic social spaces and affinity spaces. In Beyond communities of practice: Language, power and social context, eds. D. Barton and K. Tusting, 214-232. New York: Cambridge University Press.

Hummels, C., and J. Frens. 2011. Designing disruptive innovative systems, products and services: RTD process. In Industrial design: New frontiers, ed. D. A. Coelho, 147-172. London: Intech Open Access Publisher.

Isbister, K. 2011. Emotion and motion: Games as inspiration for shaping the future of interface. Interactions 18 (5): 24-27.

Jenkins, H. 2009. Confronting the challenges of participatory culture: Media education for the 21st century. Cambridge, MA: The MIT Press.

Jonas, W. 2007. Design research and its meaning to the methodological development of the discipline. In Design research now, ed. R. Michel, 187-206. Basel: Birkhäuser.

Lévy, P. 1997. Collective intelligence: Mankind's emerging world in cyberspace. Trans. R. Bononno. Cambridge, MA: Perseus Books.

Lombardi, M. M. 2007. Authentic learning for the 21st century: An overview. Educause Learning Initiative 1:1-12.

Malone, T. 1981. Toward a theory of intrinsically motivating instruction. Cognitive Science 4:333-369.

Mojang. 2011. Minecraft. [multiplatform]. Mojang/Microsoft Studios. Game. Oblinger, D., and J. Oblinger. 2005. Is it age or IT: First steps toward understanding the net generation. Educating the Net Generation 2 (1-2): 20.

Przybylski, A. K., C. S. Rigby, and R. M. Ryan. 2010. A motivational model of video game engagement. Review of General Psychology 14 (2): 154-166.

Robertson, M. 2010. Can't play, won't play. Hide\&Seek. http://www.hideandseek.net/2010/10/o6/cant-play-wont-play.

Ryan, R. M., and E. L. Deci. 200o. Self-determination theory and the facilitation of intrinsic motivation, social development, and well-being. American Psychologist 55 (1): 68-78. 
Schouten B. A. M. 2015. Playful empowerment. Inaugural address at the Amsterdam University of Applied Sciences, 12 May 2015. Amsterdam: Amsterdam University Press.

Sein, M., O. Henfridsson, S. Purao, M. Rossi, and R. Lindgren. 2011. Action design research. MIS Quarterly 35 (1): 37-56.

Shaffer, D. 2006. Epistemic frames for epistemic games. Computers \& Education 46 (3): 223-234.

Squire, K. 2003. Video games in education. International Journal of Intelligent Games \& Simulation 2 (1): 49-62.

University of Washington Center for Game Science/Department of Biochemistry. 2008. Foldit. [browser]. University of Washington. Game.

Van der Spek, E. D. 2012. Towards designing for competence and engagement in serious games. In Proceedings of the 3 rd international conference on serious games development and applications, Bremen, September 26-29, 2012, 98-109. Berlin, Heidelberg: Springer.

Voss, M. A., and C. B. Cooper. 2010. Using a free online citizen-science project to teach observation \& quantification of animal behavior. The American Biology Teacher 72 (7): 437-443.

Wikipedia. 2015. Foldit. Wikipedia. http://en.wikipedia.org/wiki/Foldit. Wired Differently. 2012. Eyewire. [browser]. MIT. Game.

Wouters, P., E. D. van der Spek, and H. van Oostendorp. 2oog. Current practices in serious game research: A review from a learning outcomes perspective. In Games-based learning advancements for multisensory human computer interfaces: Techniques and effective practices, eds. T. Connolly, M. Stansfield, and L. Boyle, 232-255. Hershey: IGI Global.

Zimmerman, E. 2007. Gaming literacy: Game design as a model for literacy in the twenty-first century. Harvard Interactive Media Review 1 (1): 23-31.

\section{About the authors}

Ellis Bartholomeus started her career as an industrial designer at the Design Academy in Eindhoven. Via signage, graphic, web, and interaction design she became a game designer and created over 50 serious games in ten years with Laika.nl. In 2010, she became eager to become involved in greater depth with the use of gaming as a medium and a tool, in order to discover and research the magical features and mysteries in play that allow a player to become more autonomous, gain competencies, and become socially more connected to others. As a game researcher and game consultant, she spends all her time in Wonderland and learning about play and motivation. 
Daniël Harmsen is a professional Game Designer at IJsfontein, based in Amsterdam, where he designs serious games for a broad audience and on a wide range of topics. One of his latest projects, The Canon of Dutch History for the Open Air Museum in Arnhem, the Netherlands, landed the Silver award at the European Design Awards 2018 and the International Award at the Museums + Heritage Awards for Excellence.

Ben Schouten is Full Professor of Playful Interactions in Intelligent Systems. In addition, he is scientific director of education at the Amsterdam University of Applied Sciences. He is an advisor for the European Commission on the Internet of Things as well as for the Dutch Cultural Media Fund, responsible for E-culture. Schouten is interested in games and play design for social innovations, citizen empowerment, and culture. Schouten was the general chair of the renowned CHI PLAY 2017 conference and co-founder of the Games for Health Conference series. He has co-edited several scientific volumes, such as the proceedings of the 5th International Joint Conference of Ambient Intelligence and the thematic issue of the Journal of Ambient Intelligent Systems (2013) on playful interactions and serious games.

Erik van der Spek is Assistant Professor of Game and Play Design. He is the chair of the Industrial Design Department Council and secretary of the International Federation for Information Processing Technical Committee on Entertainment Computing (TC14). His research interests are the design of games and play for entertainment, learning, vitality, and empathy. From playful interaction to immersive VR experiences, Van der Spek tries to discover the elements that engage us to construct imaginary magic circles, to have cathartic mediated presence experiences in fantasy environments, and that stimulate us to see the world in a newfound light. In addition to his TC14 work, Van der Spek has been the student game competition chair for CHI PLAY and supervises more than 60 student games per year, some of which have won national or international prizes and recognition. 